\title{
Modification of sensitivity of $\mathrm{BaSnO}_{3}$ sensor due to parameters of synthesis and formation of the device
}

\author{
Yasser H. Ochoa ${ }^{\text {a) }}$ \\ Department of Physics, CYTEMAC Group, University of Cauca, Popayán 90002, Colombia \\ Federico Schipani and Celso M. Aldao \\ Catalysts and Surfaces Division, INTEMA, National University of Mar del Plata, Mar del Plata 7600, Argentina \\ Jorge E. Rodríguez-Páez \\ Department of Physics, CYTEMAC Group, University of Cauca, Popayán 90002, Colombia \\ Miguel A. Ponce \\ Catalysts and Surfaces Division, INTEMA, National University of Mar del Plata, Mar del Plata 7600, Argentina
}

(Received 1 June 2015; accepted 23 September 2015)

\begin{abstract}
Powders of $\mathrm{BaSnO}_{3}$ were synthesized to obtain gas sensor thick films (using the screen printing technique) for the detection of $\mathrm{O}_{2}$ and $\mathrm{CO}$. Impedance spectroscopy was used at different atmospheres and temperatures. In the presence of $\mathrm{O}_{2}$, the films showed a maximum value of sensitivity at $300{ }^{\circ} \mathrm{C}$, with the powders formed by Pechini presenting greater reproducibility and sensitivity (with an order of magnitude greater than that for the powders formed by precipitation). Results showed that the films formed with powders obtained using the Pechini method presented a better response to $\mathrm{CO}$, with a maximum sensitivity at $450{ }^{\circ} \mathrm{C}$. In addition, in the presence of $\mathrm{CO}$ and for $T>250{ }^{\circ} \mathrm{C}$, these films showed an anomalous behavior regarding their sensitivity as a function of time when platinum electrodes were used: a great increase in the electrical resistance value for exposure times greater than $10 \mathrm{~min}$.
\end{abstract}

\section{INTRODUCTION}

The $\mathrm{BaO}-\mathrm{SnO}_{2}$ binary system is known to have three compounds: $\mathrm{BaSnO}_{3}, \mathrm{Ba}_{3} \mathrm{Sn}_{2} \mathrm{O}_{7}$, and $\mathrm{Ba}_{2} \mathrm{SnO}_{4}$. The first of the three is the best known, most researched, and most useful. Barium stannate, $\mathrm{BaSnO}_{3}$, has a cubic perovskite structure. ${ }^{1}$ It is the most widely used oxide for technological applications due to its dielectric properties, standing out as a capacitor, varistor, transparent electrocatalytic conductive electrode, and photovoltaic cell, in photocatalytic applications, and as a gas sensor. ${ }^{2-4}$ Ceramic powders of $\mathrm{BaSnO}_{3}$ are usually obtained by a solid state reaction between $\mathrm{BaCO}_{3}$ and $\mathrm{SnO}_{2}$ at $1000-1400{ }^{\circ} \mathrm{C}^{5,6}$ Other techniques that have been used include hydrothermal, ${ }^{7,8}$ considering the effect of different solvents, ${ }^{9}$ sol-gel, ${ }^{10}$ self-heat-sustained route, ${ }^{11}$ modified combustion, ${ }^{12}$ and reverse micelle method. ${ }^{13}$

The interest in this perovskite is mainly due to the easy modification of its electrical properties and its stability at high temperatures. For gas sensing, $\mathrm{BaSnO}_{3}$ is a very promising material for high-temperature detection of gases, ${ }^{2}$ particularly those gases generated in combustion processes. It has been reported that $\mathrm{BaSnO}_{3}$ has a $3.4 \mathrm{eV}$ band gap, which is within the range generally desired for gas sensor materials. ${ }^{14,15}$

Contributing Editor: José Arana Varela

${ }^{a)}$ Address all correspondence to this author.

e-mail: yochoa@unicauca.edu.co

DOI: $10.1557 /$ jmr.2015.318
In polycrystalline materials, it is widely accepted that barriers formed between particles or grains have a Schottky-type nature and this governs their electrical behavior. Adsorption of gaseous species at the grain boundaries can induce changes in barrier heights and in donor concentrations. Many oxide semiconductors are considered by the majority of researchers in the field to have a large number of oxygen vacancies, conferring their $n$-character. Barium stannate is an example of this. ${ }^{16,17}$

It is known that oxygen is chemisorbed on the grain surface, increasing the barrier height and the width of surface barriers. This is a rapid process, so that equilibrium with atmospheric oxygen would be reached quickly. Subsequently, in the second process, it was found for metal oxide semiconductors that oxygen diffuses slowly into the grains (at temperatures above $200{ }^{\circ} \mathrm{C}$ ), annihilating vacancies and reducing the donor concentration. Conversely, if oxygen diffuses out of the grains, vacancies are generated. Electron Spin Resonance measurements ${ }^{18,19}$ indicate that adsorbed oxygen is responsible for the transfer of electrons from the grains to the chemisorbed oxygen. The relevant reactions from the gas phase to the bulk of the grain for oxygen are ${ }^{18}$ :

$$
\mathrm{O}_{2(\mathrm{gas})} \leftrightarrow \mathrm{O}_{2(\mathrm{ads})} \leftrightarrow \mathrm{O}_{\text {ads }}^{-} \leftrightarrow \mathrm{O}_{\text {ads }}^{-2} \leftrightarrow \mathrm{O}_{\text {int }}^{-2} \leftrightarrow \mathrm{O}_{\text {latt }}^{-2},
$$

where $\mathrm{O}_{2 \text { (gas) }}$ refers to oxygen in the environment, $\mathrm{O}_{2(\text { ads })}$ to an oxygen molecule adsorbed at the grain surfaces, 
$\mathrm{O}_{\mathrm{ads}}^{-}$and $\mathrm{O}_{\mathrm{ads}}^{-2}$ to singly and doubly ionized monatomic oxygen at the grain surface, $\mathrm{O}_{\text {int }}^{-2}$ to interstitial oxygen, and $\mathrm{O}_{\text {latt }}^{-2}$ to oxygen in the lattice.

The operating principle of this type of sensor is based on the comparison of the electrical resistance of a semiconductor oxide film in the presence of detectable gases (carbon monoxide and oxygen, in this case). The change in the resistance depends on the gas concentration and temperature. In this work, $\mathrm{BaSnO}_{3}$ thick films were made using the screen-printing method onto alumina substrates on which electrodes with an interdigitated shape were deposited by sputtering. Measurements of capacitance and resistance were used to characterize the intergranular potential barriers. Two different $\mathrm{BaSnO}_{3}$ synthesis methods were tested (controlled precipitation and Pechini) in search of films with a good response to CO. Electrical measurements showed that both methods have a similar temperature range of responses for $\mathrm{CO}$ and $\mathrm{O}_{2}$ but their sensitivities are different. The most interesting feature of films made with the Pechini method is that the maximum sensitivity is obtained at a lower temperature range for both gases than that previously reported. ${ }^{2,20}$

\section{EXPERIMENTAL}

To obtain $\mathrm{BaSnO}_{3}$ with the Pechini method, a mixture of ethylene glycol and citric acid was first heated to $70{ }^{\circ} \mathrm{C}$, as indicated in a previous paper. ${ }^{21}$ The precursors $\mathrm{C}_{4} \mathrm{H}_{6} \mathrm{BaO}_{4}$ and $\mathrm{SnCl}_{2} \cdot 2 \mathrm{H}_{2} \mathrm{O}$, in the amounts 8.4 and $7.4 \mathrm{~g}$, respectively, were added to the ethylene glycol and citric acid solution. At room temperature, the resulting solution was brought to a basic $\mathrm{pH}$ and heated to $140{ }^{\circ} \mathrm{C}$, stirring constantly until a resin was formed. The resin was then precalcined at $350{ }^{\circ} \mathrm{C}$ and the precalcined material was heat treated within a range of temperatures $\left(T \leq 1000{ }^{\circ} \mathrm{C}\right)$ to obtain the $\mathrm{BaSnO}_{3}$. The powders obtained at the end of the synthesis processes were characterized by x-ray diffractograms (XRD) and SEM.

To obtain $\mathrm{BaSnO}_{3}$ by the controlled precipitation method, $\mathrm{SnCl}_{2} \cdot 2 \mathrm{H}_{2} \mathrm{O}$ and $\mathrm{C}_{4} \mathrm{H}_{6} \mathrm{BaO}_{4}$ were used as precursors. These were dissolved separately in $0.1 \mathrm{M}$ aqueous $\mathrm{HNO}_{3}$ solutions and the $\mathrm{pH}$ value was increased up to a basic $\mathrm{pH}$ by adding $\mathrm{NH}_{4} \mathrm{OH}$. The obtained suspensions were then mixed and left to age for $24 \mathrm{~h}$. Finally, the suspension was washed with an aqueous solution of diethylamine. The wet solid obtained was dried at $100{ }^{\circ} \mathrm{C}$ and subsequently treated at $1250{ }^{\circ} \mathrm{C}$ for $2 \mathrm{~h}$. After the synthesis process, the powders were characterized using IR Spectroscopy, XRD and SEM (JEOL 5910LV; JEOL Ltd., Tokyo, Japan). To obtain the IR Spectrum, a Thermo Nicolet IR200 (Thermo Fisher Scientific, Pittsburgh, Pennsylvania) was used. The X-ray diffractograms were obtained using the $\mathrm{X}$ TEL-X-OMETER TEL-580 with a $\mathrm{Cu}$ source $(\lambda=1.54 \AA$ ) and a 30 $\mathrm{kV}$ voltage (Tel-Atomic, Jackson, Michigan).
A paste was then prepared using an organic binder (glycerol) and the powders were synthesized. Porous thick film samples were made by painting onto a $96 \%$ dense insulating alumina substrate and were placed in a vacuum chamber at its base pressure of $10^{-6} \mathrm{~mm} \mathrm{Hg}$. Electrodes of platinum or gold, with an interdigitated shape, were then deposited by sputtering. The electrode was a platinum $200 \mathrm{~nm}$ film and was deposited over a previously deposited $25 \mathrm{~nm}$ Ti layer. ${ }^{22}$ For defining the electrodes, the substrates with the metal films were placed in a homebuilt micromachining system with a $20 \mathrm{~W}$, frequency tripled $\mathrm{Nd}: \mathrm{YVO}_{4}$ laser $(\lambda=355 \mathrm{~nm})$. The interelectrode distance was $20 \mu \mathrm{m}$. After painting, samples $F_{\mathrm{p}}$ (Pechini sample) and $F_{\mathrm{cp}}$ (controlled precipitation) were heat treated for $1 \mathrm{~h}$ in air at $100{ }^{\circ} \mathrm{C}$. This treatment was carried out to evaporate the organic binder and to improve the film adhesion to the alumina substrate. Later, the samples were preheat treated up to $380{ }^{\circ} \mathrm{C}$ using a heating rate of $1{ }^{\circ} \mathrm{C} / \mathrm{min}$. The average thickness of the films was $0.1 \mathrm{~mm}$. According to the geometry of our sensors, and taking into account that the electrical path in the interelectrode distance is shorter than that present everywhere else, an increase in the sensor thickness will only increase the response time, since it will take longer for gases to reach the interdigitated path.

The $\mathrm{BaSnO}_{3}$ film was placed in the sample holder cell of a static flow system (Fig. 1). The electrical conductivity behavior of the films, as function of temperature, was determined with a multimeter (Agilent 34401A; Keysight Technologies, Palo Alto, California). Conductivity versus temperature measurements were carried out (for the $F_{\mathrm{p}}$ and $F_{\mathrm{cp}}$ films) raising and then decreasing the temperature of the samples in the range $25-200{ }^{\circ} \mathrm{C}$ at a rate of $\sim 1{ }^{\circ} \mathrm{C} / \mathrm{min}$ with the sample first kept in vacuum $\left(10^{-4} \mathrm{~mm} \mathrm{Hg}\right)$. To gain confidence in sensor properties, resistance (at $20 \mathrm{~Hz}$ ) versus time curves were measured while changing the vacuum $\left(10^{-4} \mathrm{~mm} \mathrm{Hg}\right)$ to an $\mathrm{O}_{2}$ or $\mathrm{CO}$ atmosphere (at different $\mathrm{O}_{2}$ and $\mathrm{CO}$ concentrations of $2,4,6,8,10,20$, and $40 \mathrm{~mm} \mathrm{Hg}$ ) and, after having reached quasisaturation, impedance was measured in a frequency interval of $20 \mathrm{~Hz}-1 \mathrm{MHz}$ using an impedance analyzer HP4284A. Later, the samples were exposed again to vacuum. The sensitivity of the $\mathrm{BaSnO}_{3}$ films was determined from 230 to $540{ }^{\circ} \mathrm{C}$. It was calculated as, the resistance of the sensors in a gaseous atmosphere divided by their resistance in vacuum.

\section{CHARACTERIZATION OF SYNTHESIZED POWDERS}

\section{A. XRD measurements}

The diffractograms of Fig. 2 correspond to the solids obtained with the Pechini method, treated at $1000{ }^{\circ} \mathrm{C}$, and to the samples obtained by controlled precipitation method, treated at $1250{ }^{\circ} \mathrm{C}$ for $2 \mathrm{~h}$, since for treatments 


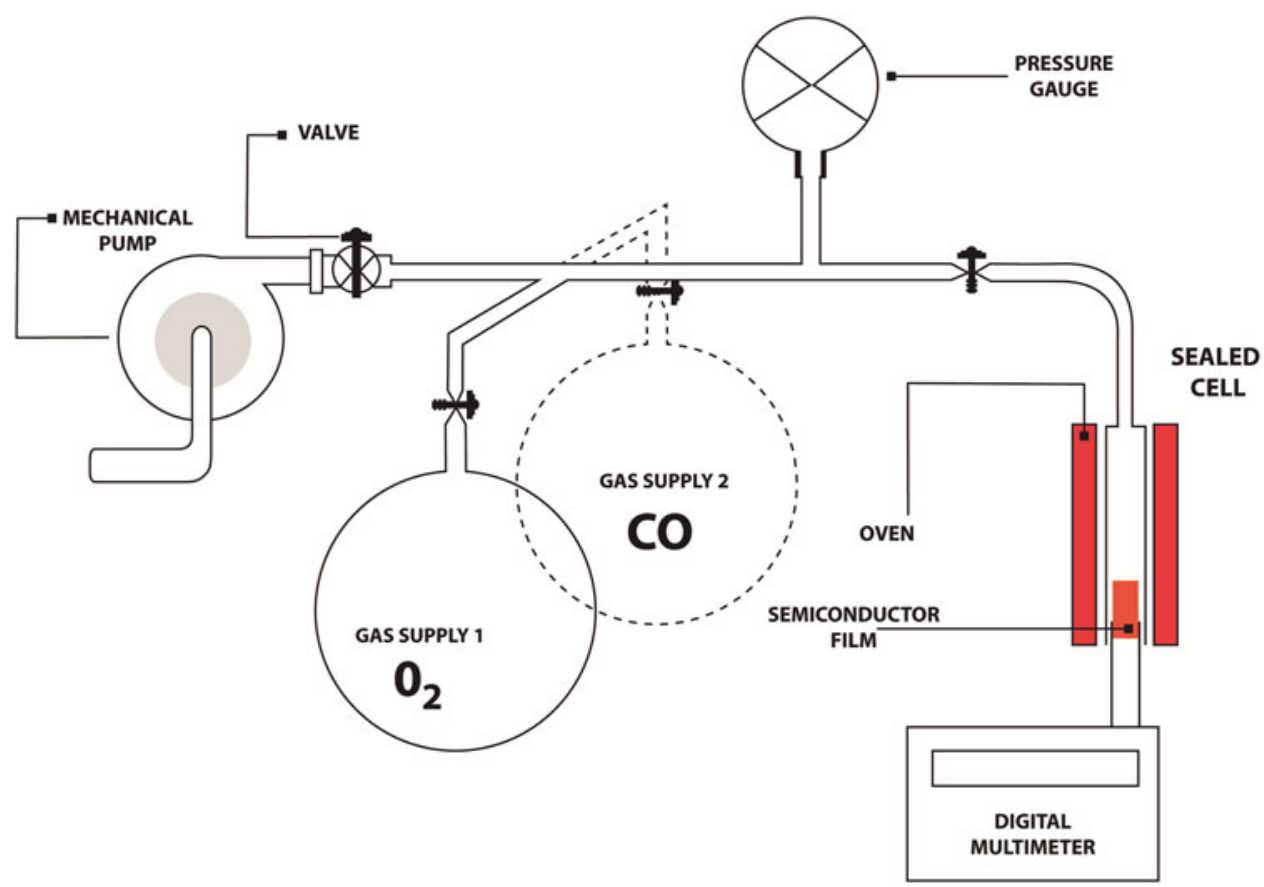

FIG. 1. Diagram of the equipment used to determine the gas sensing capacity of sensing films.

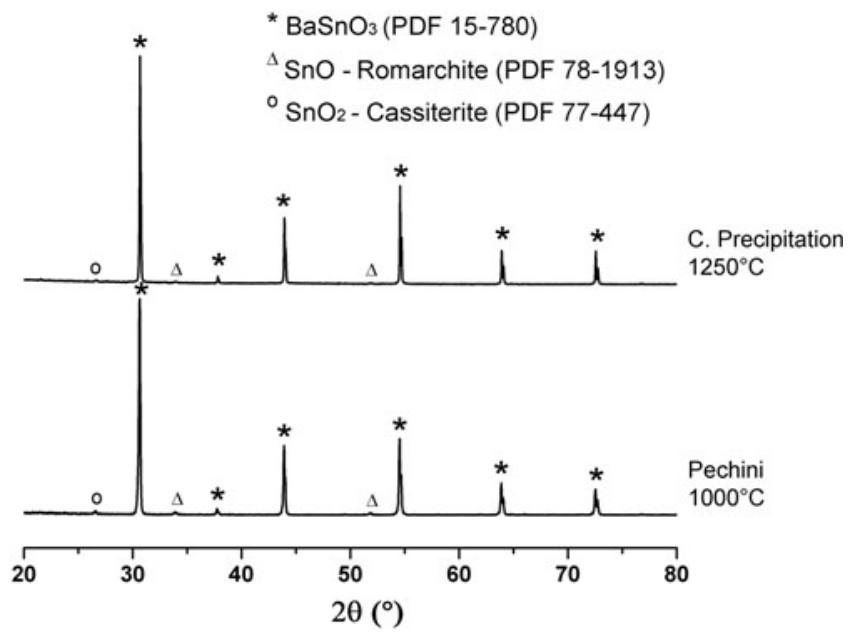

FIG. 2. XRD diffractograms of Ba-Sn system solid samples synthesized by the controlled precipitation and the Pechini methods, heat treated at 1250 and $1000{ }^{\circ} \mathrm{C}$, respectively, for $2 \mathrm{~h}$.

below $1000{ }^{\circ} \mathrm{C}$ these samples have primarily the crystalline phase of $\mathrm{SnO}_{2}$ but, when treated at higher temperatures, specifically at $1250{ }^{\circ} \mathrm{C}$, crystallization yields pure $\mathrm{BaSnO}_{3}$ as the main phase. ${ }^{21}$ Both samples show $\mathrm{BaSnO}_{3}$ (PDF 15-780) as the main crystalline phase.

\section{B. SEM images}

Figure 3 shows SEM micrographs corresponding to $\mathrm{BaSnO}_{3}$ thick films formed with ceramic powders obtained using controlled precipitation (a), and the Pechini method (b). Both samples were heat treated at $380{ }^{\circ} \mathrm{C}$. In the case of the $F_{\mathrm{cp}}$ film there is a very wide distribution in the grain size, and the images demonstrate the presence of grains larger than $5 \mu \mathrm{m}$ [Fig. 3(a)]. With the $F_{\mathrm{p}}$ film, the grains are more uniform in grain size [Fig. 3(b)]. It can also be seen that the $F_{\mathrm{cp}}$ film has a grain size of $\sim 3.5 \mu \mathrm{m}$, greater than the $\sim 1.5 \mu \mathrm{m}$ for the $F_{\mathrm{p}}$ film.

\section{Fourier transform infrared spectroscopy (FTIR)}

To obtain information on the evolution of the functional groups during crystallization of the ceramic powder, the dry powders from each synthesis method were characterized using IR spectroscopy. Figure 4 shows IR spectra corresponding to samples obtained by the controlled precipitation method, heat treated at 100, 500, 800,1000 , and $1250{ }^{\circ} \mathrm{C}$. The results indicate the presence of hydroxyls in the solid, bands around $3445 \mathrm{~cm}^{-1}$ showing the presence of absorbed water in the samples, and $\mathrm{NO}_{3}{ }^{-}$, a band located at $1361-1395 \mathrm{~cm}^{-1} \cdot{ }^{21,23}$ The most evident band is that located at $\sim 630 \mathrm{~cm}^{-1}$, corresponding to a vibrational mode of the $\mathrm{Sn}-\mathrm{O}$ group of the $\mathrm{SnO}_{3}{ }^{2-},{ }^{21,24}$ and that might be used to demonstrate the existence of $\mathrm{BaSnO}_{3}$. The band at $1422 \mathrm{~cm}^{-1}$ is associated with $\mathrm{BaCO}_{3},{ }^{21,23,25}$ so that its intensity decreased at high temperatures. This band appeared in most of the spectra indicating that the $\mathrm{BaCO}_{3}$ was found in the samples as an unwanted additional phase, which was required to be removed.

Figure 5 shows the IR spectra corresponding to solid samples obtained by the Pechini method, calcined at $350{ }^{\circ} \mathrm{C}$ and then heat treated at $500-1000{ }^{\circ} \mathrm{C}$. The spectra show a band at $3440 \mathrm{~cm}^{-1}$ that can be attributed 


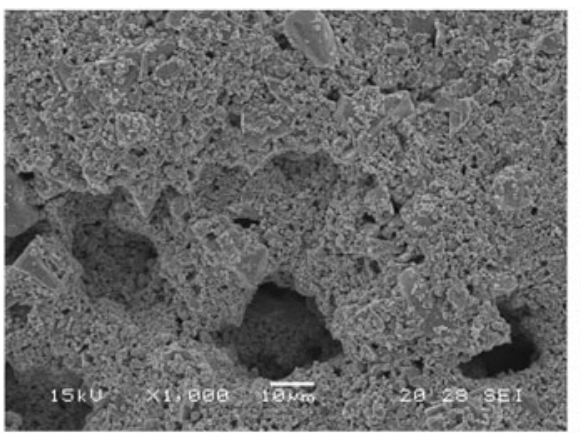

(a)

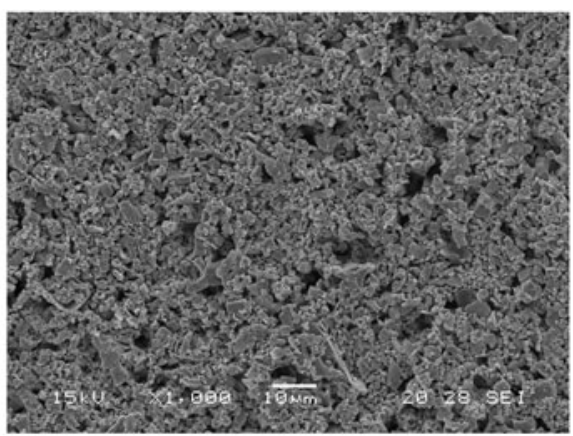

(b)

FIG. 3. SEM photographs of $\mathrm{BaSnO}_{3}$ thick porous films at different magnifications. (a) $F_{\mathrm{cp}}$ film and (b) $F_{\mathrm{p}}$ film. Both films were made by the screen printing technique.

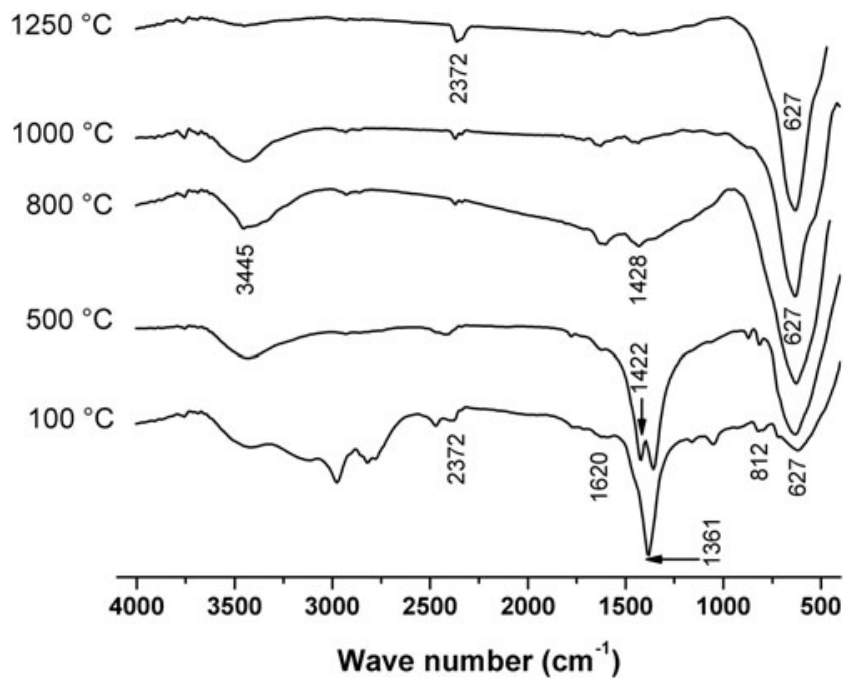

FIG. 4. IR spectra corresponding to solid samples of the $\mathrm{SnCl}_{2}-\mathrm{Ba}$ $\left(\mathrm{CH}_{3} \mathrm{COO}\right)_{2}-\mathrm{H}_{2} \mathrm{O}-\mathrm{NH}_{4} \mathrm{OH}$ system, controlled precipitation method, heat treated at different temperatures. ${ }^{21}$

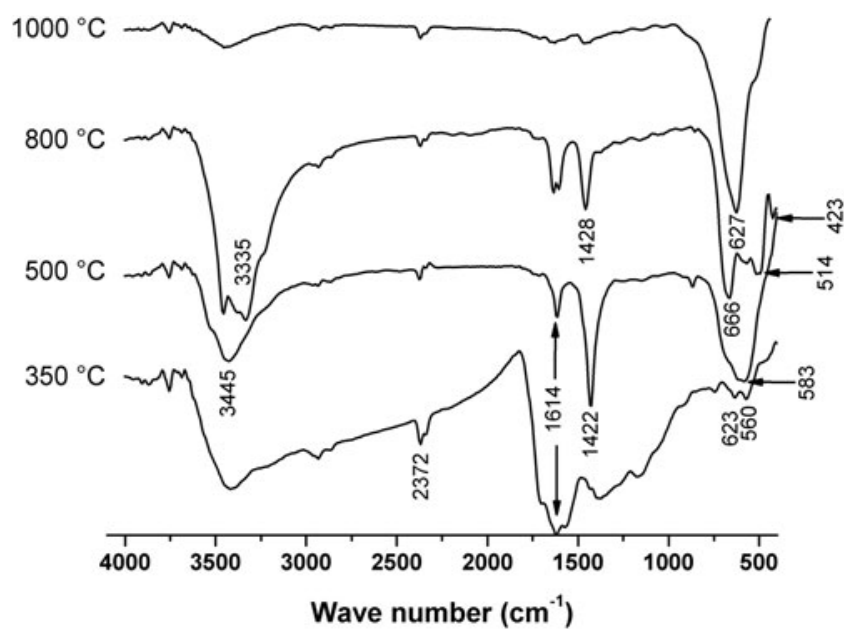

FIG. 5. IR spectra corresponding to solid samples of the $\mathrm{SnCl}_{2}-\mathrm{Ba}$ $\left(\mathrm{CH}_{3} \mathrm{COO}\right)_{2}-\mathrm{H}_{2} \mathrm{O}-\mathrm{NH}_{4} \mathrm{OH}$ system, Pechini method, heat treated at different temperatures. to the vibrational mode of the tension in the $\mathrm{H}-\mathrm{OH}$, while the band at $1630 \mathrm{~cm}^{-1}$ corresponds to the flexing mode of the water. The band at $1430 \mathrm{~cm}^{-1}$ may be associated with the vibration of residual organic $\mathrm{C}-\mathrm{H}$ groups. ${ }^{23,25}$ The band at $\sim 630 \mathrm{~cm}^{-1}$ seen in the spectra corresponds to $\mathrm{Sn}-\mathrm{O} .^{24}$ This band, considered to be a characteristic of $\mathrm{BaSnO}_{3}$, is most evident in the treatment at $1000{ }^{\circ} \mathrm{C}$.

\section{MEASUREMENTS AND RESULTS}

The sensitivity of $\mathrm{BaSnO}_{3}$ thick films was determined from 230 to $540{ }^{\circ} \mathrm{C}$. Sensitivity was calculated as, the resistance of the sensors in a gaseous atmosphere divided by their resistance in a vacuum. The concentrations of $\mathrm{O}_{2}$ and $\mathrm{CO}$ were varied between 2 and $40 \mathrm{~mm} \mathrm{Hg}$ for both types of samples, $F_{\mathrm{p}}$ and $F_{\mathrm{cp}}$. No further changes in the electrical behavior were found during exposure to gas concentrations greater than $40 \mathrm{~mm} \mathrm{Hg}$, thus $40 \mathrm{~mm} \mathrm{Hg}$ was chosen to be the highest concentration studied. Figures 6 and 7 show the sensitivity of the sensors to $\mathrm{O}_{2}$ and $\mathrm{CO}$, respectively. Although, both samples show a good sensitivity to $\mathrm{O}_{2}$ at $300{ }^{\circ} \mathrm{C}, F_{\mathrm{p}}$ presents a better response (an order of magnitude greater than that of $F_{\mathrm{cp}}$ ). For the $F_{\mathrm{p}}$ samples the sensitivity increases with the gas concentration in the range of $230-540{ }^{\circ} \mathrm{C}$.

From Fig. 6, we can conclude that the films made with powders obtained using the Pechini method present a better reproducibility, while the best operating temperature, for oxygen detection, is around $300{ }^{\circ} \mathrm{C}$. This represents a notable difference found with respect to other authors who have reported higher temperatures for maximum sensitivity to $\mathrm{O}_{2}{ }^{2,22}$

To analyze the electrical behavior of the $F_{\mathrm{p}}$ samples, it will be assumed, as is generally accepted, that barrier formation between grains is responsible for sensor conductivity and that these barriers have a Schottkytype nature. As a first approach, for barrier height calculations, researchers have regularly considered a thermionic mechanism that leads to a conductivity of the type 

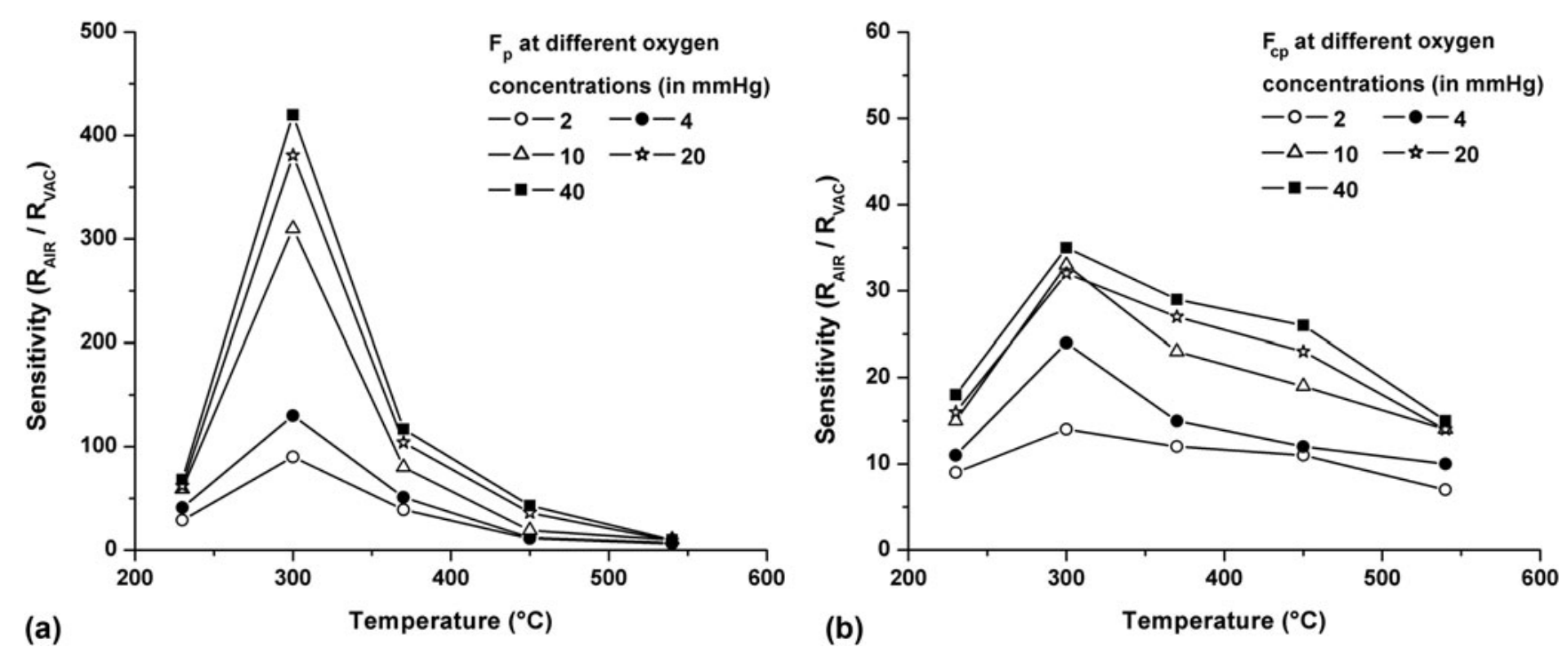

FIG. 6. Sensitivity curves of different oxygen concentrations, (a) $F_{\mathrm{p}}$ film and (b) $F_{\mathrm{cp}}$ film.
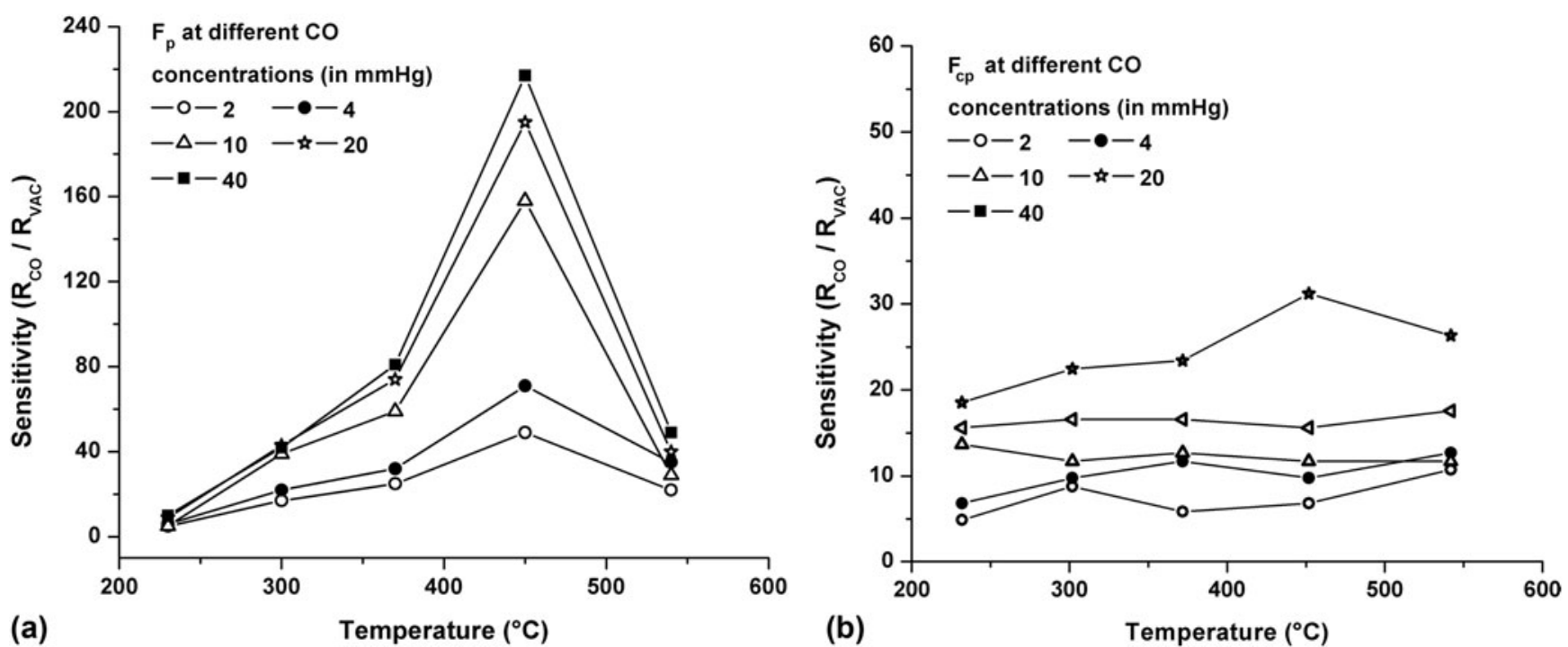

FIG. 7. Sensitivity curves for different CO concentrations, (a) $F_{\mathrm{p}}$ film and (b) $F_{\mathrm{cp}}$ film.

$$
G=G_{0} \exp (e \varphi / k T)
$$

where $e \varphi$ is the barrier height, $T$ is the temperature, and $k$ is the Boltzmann constant. This equation reflects an activated process due to intergranular barriers. As is commonly done, barrier height is estimated by plotting conductance $(\ln G)$ versus the reverse function of temperature $(1 / T)$. Thus, an activation energy $\left(E_{\mathrm{a}}\right)$ can be obtained from the slope of a fitting straight line.

Figure 8 shows the conductance in vacuum conditions of $F_{\mathrm{p}}$ samples versus the inverse of temperature, in cycling experiments. Specifically, conductance was measured by raising and then decreasing the temperature in vacuum, reaching about $200{ }^{\circ} \mathrm{C}$. In this temperature range, the room temperature conductance value is recovered after the cycle implying that no oxygen adsorption/desorption takes place during the heating and cooling processes.

At high enough working temperatures, gas in-out diffusion can take place. ${ }^{26}$ Indeed, it has been detected by the authors in previous works that an oxygen rich atmosphere alters the density of vacancies in tin oxide for temperatures greater than $300{ }^{\circ} \mathrm{C} .{ }^{27-29}$ As a result of this diffusion process, the density of vacancies changes and from this point the slope of the conductivity curve can no longer be associated with the barrier height. ${ }^{30,31}$ Accordingly, the effective activation energy obtained was $E_{F_{\mathrm{p}}}=0.52 \mathrm{eV}$ for the $F_{\mathrm{p}}$ sample. The activation energy value was found with the sample in vacuum and 


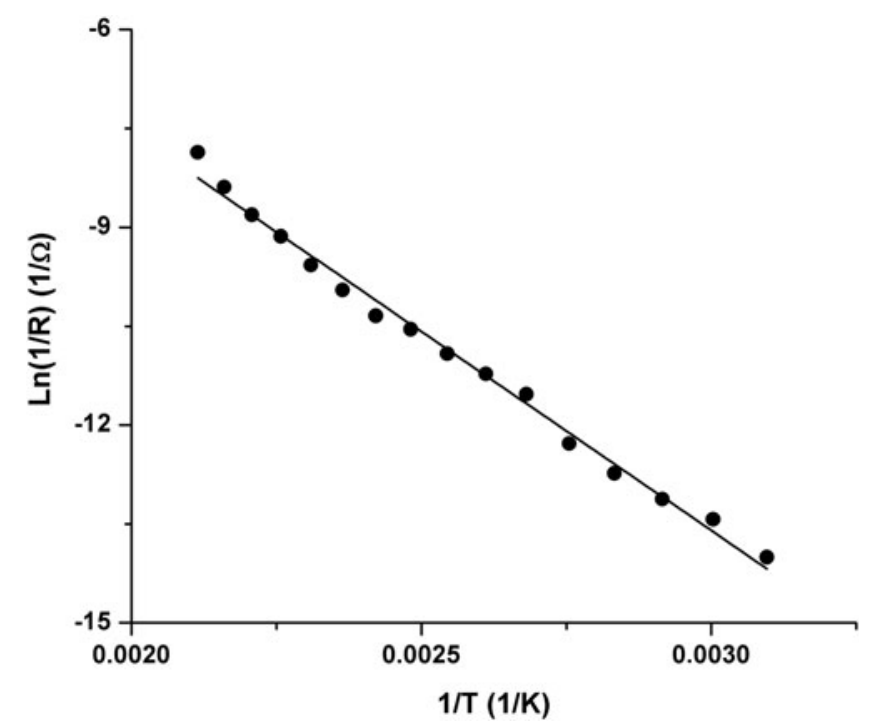

FIG. 8. Arrhenius plot for conductivity of the film in vacuum. The sample was heated to $200{ }^{\circ} \mathrm{C}$ and then cooled in vacuum to ensure no diffusion into the grains. An effective activation energy of $0.52 \mathrm{eV}$ was calculated.

considering that (i) no gas adsorption/desorption takes place during the heating and cooling processes, and that (ii) no oxygen diffusion into or out of the grains occurs during the heating or cooling within the temperature range of the study.

For nonoverlapped potential barriers, the intergrain capacitance is that of two Schottky barriers in series. In a one-dimensional approximation, the resulting capacitance when barriers are nonoverlapped, $C_{\text {no }}$, related to that corresponding to a sample with overlapped barriers, $C_{\mathrm{o}}$, can be expressed as

$$
\frac{C_{\mathrm{no}}}{C_{\mathrm{o}}}=\frac{z}{2 \Lambda}
$$

where $z$ is the grain size and $\Lambda$ is the depletion layer width. This capacitance enlargement can be interpreted, using Eq. (3), as the consequence of depletion widths that are narrower than the grain radius due to a higher doping.

To gain confidence in the present studies, capacitance measurements were carried out at $550{ }^{\circ} \mathrm{C}$ in an oxygen atmosphere and in vacuum. An atmosphere rich in oxygen will decrease the amount of oxygen vacancies, widening the potential barriers. This can lead to overlapped potential barriers. In this case, capacitance is lower and has a mild dependence with bias, as observed. Thus, from Eq. (3) and for an average grain size of $1 \mu \mathrm{m}$, the depletion layer can be estimated as

$$
\Lambda=\frac{z}{2}\left(\frac{C_{\mathrm{o}}}{C_{\mathrm{no}}}\right) \cong 1.63 \times 10^{-7} \mathrm{~m}
$$

On the other hand, in a Schottky barrier, the height $(\phi)$ and width $(\Lambda)$ are directly related ${ }^{32,33}$ :

$$
\phi=\frac{e N_{\mathrm{d}}}{2 \varepsilon} \Lambda^{2},
$$

where $N_{\mathrm{d}}$ is the donor density. Using the activation energy previously calculated and the depletion layer width, donor density can be estimated, $N_{\mathrm{d}}=3.9 \times 10^{22} 1 / \mathrm{m}^{3}$.

The conductance under vacuum was measured for $F_{\mathrm{cp}}$ samples. The conductance of the sample was much lower compared to that of $F_{\mathrm{p}}$; this is not expected as grains are three times bigger on average than in the $F_{\mathrm{p}}$ sample, so the conductance should have been higher. We present below a possible explanation for this finding. Even so, samples $F_{\mathrm{p}}$ and $F_{\mathrm{cp}}$ were both exposed to a $\mathrm{CO}$ atmosphere. Only films formed using powders obtained with the Pechini method $\left(F_{\mathrm{p}}\right)$ responded appreciably to $\mathrm{CO}$. The maximum sensitivity was reached at different times, depending on the working temperature. The response time at the highest sensitivity point was reached in 3-4 min.

To analyze the sensor behavior when samples were exposed to a $\mathrm{CO}$ atmosphere, measurements with different concentrations were obtained for samples $F_{\mathrm{p}}$ and $F_{\mathrm{cp}}$ from 230 to $540{ }^{\circ} \mathrm{C}$. In the following step, CO (from 2 to $40 \mathrm{~mm} \mathrm{Hg}$ ) was incorporated into the gas chamber. Only the samples prepared using the Pechini method presented an appreciable sensitivity and reproducible responses. The maximum sensitivity value was detected at $450{ }^{\circ} \mathrm{C}$ with no change for $\mathrm{CO}$ concentrations greater than $40 \mathrm{~mm} \mathrm{Hg}$.

It is known that carbon monoxide reacts with the oxygen adsorbed on the tin oxide surface according to these equations, ${ }^{34}$

$$
\begin{gathered}
\mathrm{O}_{2}(\mathrm{~g})+2(\equiv \mathrm{S})+2 \mathrm{e}^{\prime} \leftrightarrow 2 \mathrm{O}_{\text {ads }}^{\prime}, \\
\mathrm{O}_{\text {ads }}^{\prime}+\mathrm{CO}(\mathrm{g}) \leftrightarrow \mathrm{CO}_{2 \mathrm{ads}}+\mathrm{e}^{\prime}, \\
\mathrm{CO}_{2 \mathrm{ads}} \leftrightarrow \mathrm{CO}_{2}(\mathrm{~g})+(\equiv \mathrm{S}),
\end{gathered}
$$

where $(\equiv \mathrm{S})$ corresponds to a site on the surface where oxygen can be adsorbed. This reduction in the amount of oxygen makes the sample conductivity higher. This means that the barrier height and the depletion width $(\Lambda)$ decrease if oxygen is previously adsorbed on the surface.

In Table I, a clear distinction can be seen between sensitivities corresponding to $F_{\mathrm{p}}$ and $F_{\mathrm{cp}}$ samples. For the Pechini-made films $\left(F_{\mathrm{p}}\right)$, the high sensor response to oxygen at $300{ }^{\circ} \mathrm{C}$ contrasts with the low response to $\mathrm{CO}$ at that temperature. Conversely, at $450{ }^{\circ} \mathrm{C}$ the high sensitivity is observed to $\mathrm{CO}$ and the low one to oxygen. The $F_{\mathrm{cp}}$ sensor meanwhile shows almost no 
TABLE I. Sensitivity comparison between $F_{\mathrm{p}}$ and $F_{\text {cp }}$ samples at 40 $\mathrm{mm} \mathrm{Hg}$ of oxygen and $\mathrm{CO}$.

\begin{tabular}{lcr}
\hline \hline & $300{ }^{\circ} \mathrm{C}$ & $450{ }^{\circ} \mathrm{C}$ \\
\hline$F_{\mathrm{p}}$ in $\mathrm{CO}$ & 42 & 217 \\
$F_{\mathrm{p}}$ in $\mathrm{O}_{2}$ & 420 & 45 \\
$F_{\mathrm{cp}}$ in $\mathrm{CO}$ & 23 & 32 \\
$F_{\mathrm{cp}}$ in $\mathrm{O}_{2}$ & 35 & 26 \\
\hline \hline
\end{tabular}

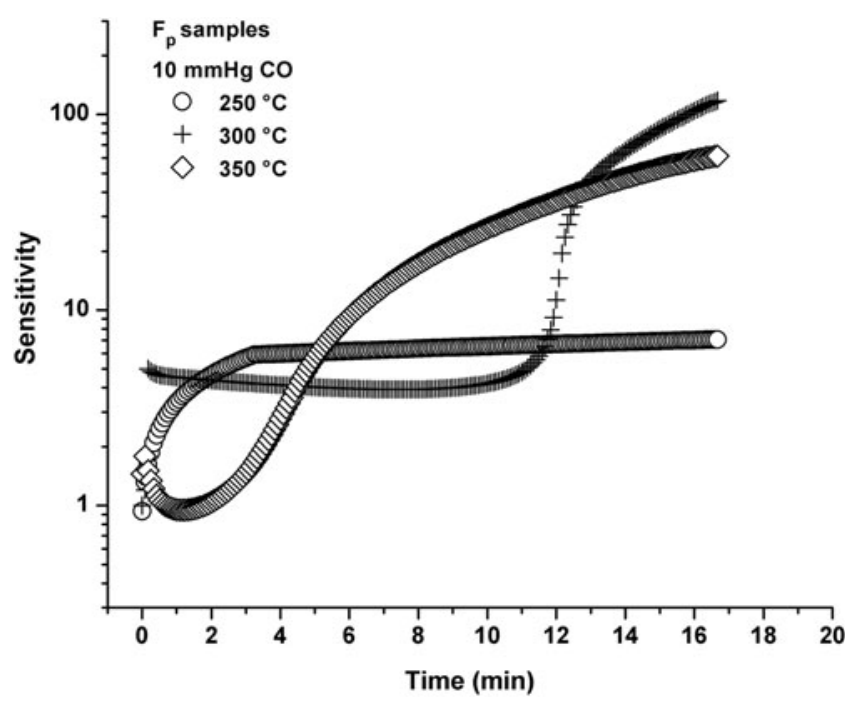

FIG. 9. Sensitivity curves at three different temperatures for $F_{\mathrm{p}}$ samples with platinum electrodes. This anomalous effect was observed above $250{ }^{\circ} \mathrm{C}$ at all $\mathrm{CO}$ concentrations tested. At $300{ }^{\circ} \mathrm{C}$, the film resistance remains almost constant for $10 \mathrm{~min}$, and then it increases very rapidly.

difference in sensitivity between gases at these temperatures. This lack of selectivity and low sensitivity could be explained taking account of the fact that the controlled precipitation, having a $3.5 \mu \mathrm{m}$ average grain size, could not allow grain boundaries to reach complete equilibrium with the atmosphere, even at the highest temperatures. Oxygen could not in/out-diffuse to reach the grain boundary completely, in a way that the inner part of the interface would remain unaltered in spite of a changing atmosphere. This "trapped oxygen" hypothesis can also explain the lower conductance of the $F_{\text {cp }}$ sample.

Interestingly, an anomalous response was found at temperatures greater than $250{ }^{\circ} \mathrm{C}$ for $F_{\mathrm{p}}$ samples exposed to $\mathrm{CO}$. A great increase in the electrical resistance value for exposure times greater than $10 \mathrm{~min}$ was observed, as shown in Fig. 9. This striking resistance response could be due to a catalytic reaction of $\mathrm{CO}$ produced by the platinum in contact with the film. To test this hypothesis, substrates with $\mathrm{Au}$ contacts were prepared by following the same procedure as that used for Pt contacts. The anomalous effect was not found in samples prepared with Au contacts (Fig. 10).

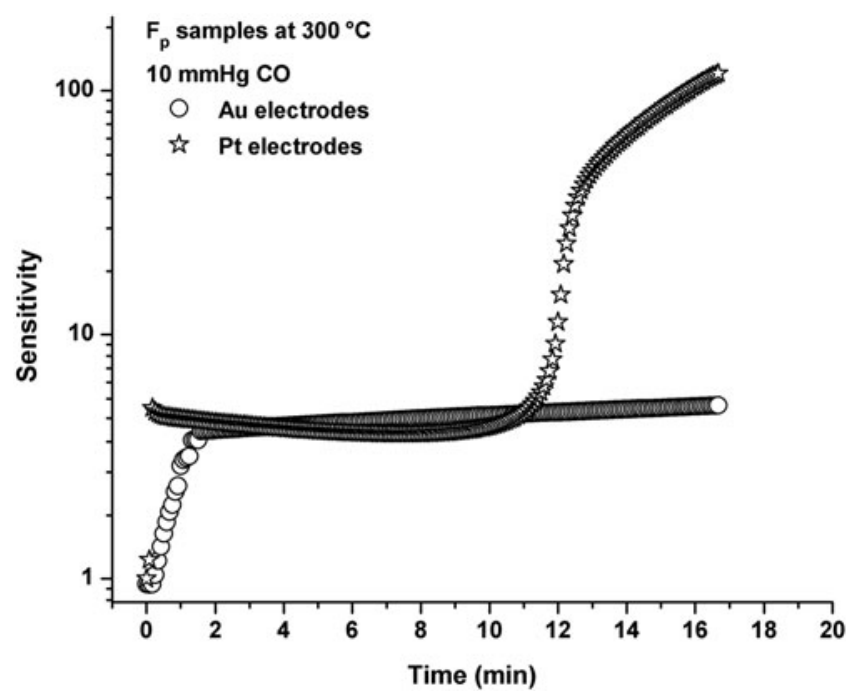

FIG. 10. Sensitivity curves of $F_{\mathrm{p}}$ samples with gold and platinum electrodes. The anomalous response only appears when platinum electrodes are used.

During the $\mathrm{CO}$ exposure for Au electrodes, no changes in the resistance were found for films prepared with either the controlled precipitation method or the Pechini method. Figure 10 shows the electrical resistance behavior when $F_{\mathrm{p}}$ samples (interdigitated electrodes of $\mathrm{Au}$ and $\mathrm{Pt}$ ) were exposed to $10 \mathrm{~mm} \mathrm{Hg}$ at $300{ }^{\circ} \mathrm{C}$.

\section{CONCLUSIONS}

In this work, $\mathrm{BaSnO}_{3}$ powders were obtained using two different methods, Pechini and controlled precipitation. $\mathrm{BaSnO}_{3}$ grains obtained with the controlled precipitation method were larger than the grains obtained with Pechini's method. Powders were screen printed on substrates and tested as gas sensors. Both films showed the maximum sensitivity to oxygen at the same temperature, but the response to oxygen was stronger for films obtained using Pechini powders. The electrical resistance of the controlled precipitation films $\left(F_{\mathrm{cp}}\right)$ was consistently higher than for Pechini's method films $\left(F_{\mathrm{p}}\right)$. This could be a consequence of the trapped oxygen in the interfaces that could not diffuse out of the grains. The use of the Arrhenius equation and impedance spectroscopy measurements permits to obtain the barrier height and the donor concentration in a vacuum atmosphere.

Regarding the response to carbon monoxide, only films prepared with the Pechini method had an appreciable sensitivity. It can be concluded that samples prepared with the Pechini method perform better as $\mathrm{CO}$ and oxygen sensors. It is important to note that the maximum gas response with the $F_{\mathrm{p}}$ samples was reached at $300{ }^{\circ} \mathrm{C}$ for oxygen and $450{ }^{\circ} \mathrm{C}$ for carbon monoxide. These temperatures are lower than those reported by 
other authors. Using sputtered platinum as interdigitated electrodes, an enhancement in the $\mathrm{CO}$ response was observed.

\section{ACKNOWLEDGMENTS}

We are grateful to the VRI of the University of Cauca for the funding of project ID 3587 and for providing logistical support. We are also grateful to Colin McLachlan for suggestions relating to the English text.

\section{REFERENCES}

1. H.D. Megaw: Crystal structure of double oxides of the perovskite type. Proc. Phys. Soc. 58(2), 133-152 (1946).

2. J. Cerda, J. Arbiol, G. Dezanneau, R. Díaz, and J.R. Morante. Perovskite-type $\mathrm{BaSnO}_{3}$ powders for high temperature gas sensor applications. Sens. Actuators, B 84, 21-25 (2002).

3. Y. Yuan, J. Lv, and X. Jiang: Large impact of strontium substitution on photocatalytic water splitting activity of $\mathrm{BaSnO}_{3}$. Appl. Phys. Lett. 91, 094107 (2007).

4. Z. Zhigang and Z. Gang: BTS: A new ferroelectric for multifunctional sensors. Ferroelectrics 101, 43-54 (1990).

5. T. Huang, T. Nakamura, M. Itoh, Y. Inaguma, and O. Ishiyama: Electrical properties of $\mathrm{BaSnO}_{3}$ in substitution of antimony for tin and lanthanum for barium. J. Mater. Sci. 30, 1556-1560 (1995).

6. S. Upadhyay, O. Parkash, and D. Kumar: Solubility of lanthanum, nickel and chromium in barium stannate. Mater. Lett. 49, 251-255 (2001).

7. W. Lu and H. Schmidt: Hydrothermal synthesis of nanocrystalline $\mathrm{BaSnO}_{3}$ using a $\mathrm{SnO}_{2} \cdot x \mathrm{H}_{2} \mathrm{O}$ sol. J. Eur. Ceram. Soc. 25, 919-925 (2005).

8. W. Lu and H. Schmidt: Synthesis of tin oxide hydrate $\left(\mathrm{SnO}_{2} \cdot x \mathrm{H}_{2} \mathrm{O}\right)$ gel and its effects on the hydrothermal preparation of $\mathrm{BaSnO}_{3}$ powders. Adv. Powder Technol. 19, 1-12 (2008).

9. W. Lu and H. Schmidt: Lyothermal synthesis of nanocrystalline $\mathrm{BaSnO}_{3}$ powders. Ceram. Int. 34, 645-649 (2008).

10. W. $\mathrm{Lu}$ and $\mathrm{H}$. Schmidt: Synthesis of nanosized $\mathrm{BaSnO}_{3}$ powders from metal isopropoxides. J. Sol-Gel Sci. Technol. 42, 55-64 (2007).

11. A.M. Azad, L.W. Shyan, T.Y. Pang, and C.H. Nee: Microstructural evolution in $\mathrm{MSnO}_{3}$ ceramics derived via self-heat-sustained (SHS) reaction technique. Ceram. Int. 26, 685-692 (2000).

12. A.S. Deep, S. Vidya, P.C. Manu, S. Solomon, A. John, and J.K. Thomas: Structural and optical characterization of $\mathrm{BaSnO}_{3}$ nanopowder synthesized through novel combustion technique. J. Alloys Compd. 509, 1830-1835 (2011).

13. J. Ahmed, C.K. Blakely, S.R. Bruno, and V.V. Poltavets: Synthesis of $\mathrm{MSnO}_{3}(\mathrm{M}=\mathrm{Ba}, \mathrm{Sr})$ nanoparticles by reverse micelle method and particle size distribution analysis by whole powder pattern modeling. Mater. Res. Bull. 47, 2282-2287 (2012).

14. G. Larramona, C. Gutierrez, I. Pereira, M.R. Nunes, and F.M.A. Da Costa: Characterization of the mixed perovskite $\mathrm{BaSn}_{1-x} \mathrm{Sb}_{x} \mathrm{O}_{3}$ by electrolyte electroreflectance, diffuse reflectance, and x-ray photoelectron spectroscopy. J. Chem. Soc., Faraday Trans. 85, 907 (1989).

15. M.J. Madou and S.R. Morrison: Chapter 3. In Chemical Sensing with Solid State Devices, Academic Press: New York, 1989.
16. Y. Shimizu, Y. Fukuyama, T.N. Narikiyo, H. Arari, and T. Seiyama: Perovskite-type oxides having semiconductivity as oxygen sensors. Chem. Lett. 14, 377-380 (1985).

17. B. Ostrick, M. Fleischer, and H. Meixner: High-temperature Hall measurements on $\mathrm{BaSnO}_{3}$ ceramics. J. Am. Ceram. Soc. 80(8), 2153-2156 (1997)

18. N. Yamazoe, J. Fuchigami, M. Kishikawa, and T. Seiyama: Interactions of tin oxide with $\mathrm{O}_{2}, \mathrm{H}_{2} \mathrm{O}$ and $\mathrm{H}_{2}$. Surf. Sci. 86, 335 (1979).

19. S.C. Chang: Oxygen chemisorption on tin oxide: Correlation between electrical conductivity and EPR measurements. J. Vac. Sci. Technol. 17, 366 (1980).

20. U. Lampe, J. Gerblinger, and H. Meixner: Carbon-monoxide sensors based on thin films of $\mathrm{BaSnO}_{3}$. Sens. Actuators, B $\mathbf{2 5}$, 657-660 (1995).

21. Y.H. Ochoa-Muñoz, M.A. Ponce, and J.E. Rodríguez-Páez: Comparative study of two wet chemical methods of $\mathrm{BaSnO}_{3}$ synthesis: Mechanism of formation of mixed oxide. Powder Technol. 279, 86-95 (2015).

22. C.M. Aldao, F. Schipani, M.A. Ponce, and E. Joanni, F.J. Williams: Conductivity in $\mathrm{SnO}_{2}$ polycrystalline thick film gas sensors: Tunneling electron transport and oxygen diffusion. Sens. Actuators, B 193, 428-433 (2014).

23. G. Socrates: Infrared and Raman Characteristic Group Frequencies: Tables and Charts, 3rd ed. (John Wiley \& Sons Ltd., West Sussex, 2001).

24. D. Amalric-Popescu and F. Bozon-Verduraz: Infrared studies on $\mathrm{SnO}_{2}$ and $\mathrm{Pd} / \mathrm{SnO}_{2}$. Catal. Today 70, 139-154 (2001).

25. K. Nakamato: Infrared and Raman Spectra of Inorganic and Coordination Compounds, Part A, B, 5th ed. (John Wiley \& Sons Inc., New York, 1997).

26. M. Batzill and U. Diebold: The surface and materials science of tin oxide. Prog. Surf. Sci. 79, 47-154 (2005).

27. M. Ponce, C.M. Aldao, and M.S. Castro: Influence of particle size on the conductance of $\mathrm{SnO}_{2}$ thick films. J. Eur. Ceram. Soc. 23, 2105-2111 (2003).

28. C.M. Aldao, D.A. Mirabella, M.A. Ponce, A. Giberti, and C. Malagù: Role of intragrain oxygen diffusion in polycrystalline tin oxide conductivity. J. Appl. Phys. 109, 063723 (2011).

29. C. Malagu, M.C. Carotta, A. Giberti, V. Guidi, G. Martinelli, M.A. Ponce, M.S. Castro, and C.M. Aldao: Two mechanisms of conduction in polycrystalline $\mathrm{SnO}_{2}$. Sens. Actuators, B 136, 230234 (2009)

30. F. Schipani, C.M. Aldao, and M.A. Ponce: Schottky barriers measurements through Arrhenius plots in gas sensors based on semiconductor films. AIP Adv. 2, 2158-3226 (2012).

31. M.A. Ponce, M.S. Castro, and C.M. Aldao: Influence of oxygen adsorption and diffusion on the overlapping of intergranular potential barriers in $\mathrm{SnO}_{2}$ thick films. Mater. Sci. Eng., B 111, 14-19 (2004).

32. S.M. Sze: Physics of Semiconductor Devices, 3rd ed. (John Wiley \& Sons, New Jersey, 1981).

33. K.C. Kao: Dielectric Phenomena in Solids, 1st ed. (Elsevier Academics Press, New York, 2004).

34. M.A. Ponce, C. Malagu, M.C. Carotta, G. Martinelli, and C.M. Aldao: Gas in-diffusion contribution to impedance in tin oxide thick films. J. Appl. Phys. 104, 054907 (2008). 